\title{
12
}

\section{IMPLEMENTING GLOBAL INFORMATION TECHNOLOGY PRODUCT IN A LOCALIZED CONTEXT}

\author{
An Exploratory Study of ERP System Implementation in China
}

\author{
Gary S C Pan ${ }^{1}$, Shan L Pan ${ }^{2}$, Xin-Xin Chen ${ }^{2}$ and Donal Flynn ${ }^{1}$ \\ ${ }^{\prime}$ Department of Computation, University of Manchester Institute of Science and Technology; \\ ${ }^{2}$ Department of Information Systems, School of Computing National University of Singapore;
}

\begin{abstract}
This multiple-case study examines the phenomenon of implementing a global information technology product in a localized context. The study attempts to explore issues related to the localization experience encountered by ERP adopters in China. Specifically, the paper explores ERP system implementation in five organizations in China. Despite its potential, ERP is considered one of the most difficult systems to implement to date. The risk of implementing an ERP package in China is even higher due to the relatively backward, nonstandard management mechanisms and business processes operating in this environment. Taking into account these weaknesses, this paper argues that BPR could play a significant role in ERP deployment. As the concept of ERP is still new to Chinese enterprises, it is natural that relatively few organizations were found to have carried out BPR as a preparatory step for ERP implementation. By developing an understanding of the importance of BPR, we derive five important findings based on the case studies. These comprise what literature suggests as key issues for an ERP implementation and integrate what our research revealed as essential issues for organizations implementing a global IT product in a localized context.
\end{abstract}

Keywords: Enterprise resource planning systems, business process reengineering, developing countries, multiple case study and global product. 


\section{INTRODUCTION}

Enterprise Resource Planning (ERP), is an enterprise-wide package that integrates all necessary business functions into a single system with a shared database (Lee and Lee, 2000; Newell et al., 2003). Evolving from Material Requirement Planning (MRP) systems, ERP systems have flourished in recent years, and sales of ERP systems are expected to remain high at US $\$ 16$ billion through 2004 (AMR, 2002). While there is wide acceptance of ERP in developed countries, developing countries such as China still lag far behind as many of its organizations have just started automating business processes using computer information systems (Reimers, 2002). Currently, China is undergoing a technological change with huge information technology (IT) investments in both public and private sectors. Its rapid economic growth has turned it into a major target for large foreign ERP vendors. These foreign vendors hold approximately $70 \%$ of the ERP market share in China (CCID, 2000). The ERP industry can be seen as an example of China's increased emphasis on IT. This paper argues that it is interesting to explore the implementation issues of ERP systems of both foreign- and locally-owned organizations in China.

While many Western enterprises have achieved successes in their ERP implementations (Scheer and Habermann, 2000; Somers and Nelson, 2001), ERP implementation should not be seen as a universal solution (Soh et al., 2000). This is because several complex issues need to be resolved for successful implementation, such as smoothing out irregularities in business processes and introducing management standards (Krumbholz et al., 2000), and overcoming massive resistance to change (Jin, 2001). In addition, research suggests that there are difficulties in localizing foreign ERP packages, which often results in ERP failures (Holland and Light, 1999; Krumbholz et al., 2000). Acknowledging the difficulties in implementing a global IT product in a localized environment, the paper proposes a bundling strategy for ERP implementation. Specifically, it is recommended that a company conduct a series of business process reengineering (BPR) activities before actual ERP implementations.

The research on which this paper is based involved a number of exploratory studies in the context of a developing country that has not been widely researched previously, i.e., China. Despite Chinese organizations' fast growing demand for ERP systems in recent years, there are challenges in developing countries that are related to economic, cultural, and basic infrastructure issues, which have been relatively neglected in the mainstream IS literature (Huang and Palvia, 2001). In particular, based on data collected from five Chinese organizations, we examine the possibility of bundling BPR with ERP implementation to help improve the overall project success. 
After the introduction, the rest of the paper is structured as follows. First, we describe the research approach employed in this study. Next, in the main sections of the paper, we provide a detailed description and analysis of five ERP cases in China. Finally, we draw conclusions on how our paper addresses its goals.

\section{RESEARCH DESIGN AND METHODS}

The research for our study is best described as exploratory and descriptive of the emerging ERP market in China which aims to develop an understanding of the issues concerning BPR before ERP implementations. A case study approach is selected and is deemed appropriate because of the exploratory nature of this research (Walsham, 1993; 1995; Newman and Sabherwal, 1996). One advantage of using the case study method is its ability to explain what goes on in organisations and it is also particularly good for answering the 'how' and 'why' questions (Yin, 1994).

Table 1. ERP Case Studies in China

\begin{tabular}{|c|c|c|c|c|c|}
\hline Case & Company A & Company B & Company C & Company D & Company E \\
\hline Location & $\begin{array}{c}\text { Suzhou } \\
\text { China }\end{array}$ & Wuxi China & $\begin{array}{c}\text { Suzhou } \\
\text { China }\end{array}$ & $\begin{array}{c}\text { Suzhou } \\
\text { China }\end{array}$ & $\begin{array}{c}\text { Suzhou } \\
\text { China }\end{array}$ \\
\hline $\begin{array}{l}\text { Property of } \\
\text { Organization }\end{array}$ & $\begin{array}{l}\text { Foreign- } \\
\text { funded } \\
\text { Company }\end{array}$ & $\begin{array}{c}\text { Sino } \\
\text { Australian } \\
\text { Joint } \\
\text { Venture } \\
\end{array}$ & $\begin{array}{l}\text { Foreign- } \\
\text { funded } \\
\text { Company }\end{array}$ & $\begin{array}{l}\text { Foreign- } \\
\text { funded } \\
\text { Company }\end{array}$ & $\begin{array}{l}\text { Foreign- } \\
\text { funded } \\
\text { Company }\end{array}$ \\
\hline $\begin{array}{l}\text { Location of } \\
\text { Headquarters }\end{array}$ & U.S. & Australia & U.S. & U.S. & Australia \\
\hline Industry & $\begin{array}{l}\text { Integrated } \\
\text { Circuits }\end{array}$ & $\begin{array}{c}\text { Beer \& } \\
\text { Beverage }\end{array}$ & $\begin{array}{l}\text { Automotive } \\
\text { Systems }\end{array}$ & $\begin{array}{l}\text { Audio } \\
\text { Products }\end{array}$ & $\begin{array}{c}\text { Beer \& } \\
\text { Beverage }\end{array}$ \\
\hline $\begin{array}{l}\text { Number of } \\
\text { employees } \\
\text { worldwide }\end{array}$ & 14,000 & 175,000 & 195,000 & 10,000 & 175,000 \\
\hline $\begin{array}{l}\text { ERP systems } \\
\text { Adopted }\end{array}$ & SAP & QAD & Fourth Shift & U8 & QAD \\
\hline $\begin{array}{c}\text { No. Of } \\
\text { interviewees }\end{array}$ & 10 & 10 & 15 & 11 & 17 \\
\hline
\end{tabular}

The data collection was undertaken between January 2002 and July 2002, through interviews and reviews of secondary data such as internal 
documents, minutes of meetings, company reports, numerous press releases and relevant websites. Table 1 above outlines the case companies and the number of interviewees from each company. Each interview lasted approximately 1.5 to 2 hours and was tape-recorded. Interview questions were semi-structured. In terms of data analysis, several concepts, themes and issues were identified and developed by the authors. The analysis went through several iterations to put together a logical overview of issues concerning BPR in those ERP implementation experiences in China.

\section{CASE STUDIES}

\subsection{Company A}

Company $\mathrm{A}$ is a subsidiary of a Fortune 500 company, which is a manufacturer of integrated circuits for personal and networked computers. The company's headquarters are based in the United States, with manufacturing facilities worldwide. Its China plant is in Suzhou and employs approximately 700 employees. The company had selected SAP as its ERP solution, at the request from their headquarters. Before the SAP implementation, Company A had legacy systems in all of its departments. The implementation process of SAP consisted of four phases where the legacy system was replaced by one ERP module in every phase. When asked about the project, the chairman of the company commented, "Before we kicked off the entire implementation, we had to review our existing business processes and identify some of 'our weaknesses in our processes."

The project manager who was in-charge of the ERP implementation also added, "From the beginning, we instructed our implementation team that the process should be done one step at a time because numerous "mismatches' could occur and we should avoid speeding up any procedure irrationally." Employees in company A seemed optimistic about the project. For example, one of the end users commented, "Everyone in the company was fully aware of the system implementation and its importance. We were prepared to accept any change". Another informant also said, "I think innovation is encouraged in this company. If you can invent a feasible idea, your idea may be evaluated, adopted and rewarded by the company."

\subsection{Company B}

Company B was previously a Chinese state-owned beverage company, before being taken over by an Australian beer and beverage group in 1995. 
In 1998, company B implemented most of the modules in the QAD systemsthe ERP solution used by the headquarters in Australia. Being an ex-state enterprise, most of its employees were middle-aged and had rarely operated computers. This resulted in some difficulties in conducting user trainings. When asked to comment on the users' computer knowledge, one of the system analysts replied that, "Once I received a call inquiring about the operation of the system. Guess what? I even had to go over the basic computer knowledge by telling that person where the 'start' button was located."

Moreover, most middle-aged users studied Russian in school (in their early days, they were taught Russian rather than English as their foreign language). They did not understand English language at all. When asked how the users' limited knowledge of English had affected the implementation process, one of the system analysts spoke of his frustrations; "Once I asked one end user who had called for help, what system error message was on his screen, he answered me by spelling a whole sentence letter by letter."

These problems are often witnessed in state-owned enterprises or ex state-owned enterprises, which are traditionally managed with structured business processes and are less prepared and willing to go through radical changes. Such corporate cultures tend to be more conservative which imply that unknown or radical changes are often avoided whenever possible.

The other problem often mentioned by the respondents was the high turnover of personnel during the ERP implementation process. With process automation, job scopes were redesigned or positions were reshuffled. This set off a series of problems in terms of staff morale and productivity. When asked to highlight the problems that had surfaced, one manager commented, "For example, how to lay off redundant staffs without causing grievances among them? Who is supposed to be in charge of these changes? We didn't foresee such a great change involved in ERP implementation, we did not prepare before it occurred. We tried to lay off as few staff as possible since they all had worked for the company for a long time."

\subsection{Company $\mathbf{C}$}

Company $\mathrm{C}$ is a subsidiary of an American conglomerate, which is a market leader in the mobile electronics and transportation system industry. It has a workforce of 300 in China and its headquarters are based in the US. While both its headquarters and the branch in Singapore are operating on SAP systems, Company $\mathrm{C}$ had instead opted for the Fourth-Shift ERP solution over other renowned ERP systems due to the issue of cost. 
One problem that occurred during its implementation was the software customization. Having recognized many 'mismatches' between the functionalities in the ERP package and the business processes adopted in the financial department, the implementation team opted to customize the financial and accounting module by developing another fixed asset module during the implementation of the financial module.

However, some of the implementation team members had left the company soon after the customization. This had posed serious problems because the new staff had difficulty maintaining the customized module as they had little knowledge on how the former designers developed the module. This had resulted in the financial department encountering a lot of problems in operating their system. In the end, the financial module was abandoned. When asked to comment on the issue, the finance director said, "This customized module really drove me crazy. We wasted too much time and effort on it and now, nobody is able to take care of it any further".

\subsection{Company D}

Company D is a subsidiary of an American company that produces a full range of high-quality audio and video products, which employs approximately 400 employees in China. Company D had adopted a local ERP package named U8 and the entire implementation process lasted two months. There were no major "mismatches" in adopting the ERP solution. The company simply reengineered its business processes to be consistent with the standard models and configured the system according to its requirements. Company $\mathrm{D}$ also added some bolt-ons for additional functionalities.

On the whole, the company was satisfied with U8. As the financial director commented, "We are satisfied with this U8 ERP package in terms of its simplicity, low cost and vendor's prompt support. Moreover, we enjoy a very close relationship with the service engineers from U8's branch in Suzhou. We know that they will always be there while we adjust ourselves with new processes and environment."

In addition, the vendor offered strong customization support to help clients to resolve all kinds of problems according to the specific situation faced by each customer. The vendors also helped to resolve any bugs in the software and continuously provided training to new users.

\subsection{Company E}

Company $\mathrm{E}$ is an Australian owned beer and beverage plant that employs 400 staff in China. Company E had implemented the QAD ERP solution in 
1997. All the employees, facilities and business processes were newly established and therefore, the implementation process was relatively smooth. When asked to comment on why the implementation was relatively successful, one of the IS analysts commented, "Good interdepartmental communication is the key factor, I must say. For example, frequent communication, lots of feedback on how to improve on our own processes to 'fit' the new ideas in the systems and total cooperation from members from various departments."

Another key success factor cited was a well-defined objective. One of the informants commented, "I think the clearly defined goals are important for us. We were clear and determined with what we need, with every department coping comfortably with the requirements."

When asked to comment about how the ERP system impacted their work, one project member of the ERP implementation team said, "We did not experience very dramatic change after we implemented ERP. Even if there were some changes, we were flexible and should be able to adapt easily."

\section{FINDINGS}

Since BPR is an important issue in ERP implementations (Bingi et al., 1999; Holland et al., 1999; Sumner, 1999; Holland and Light, 1999; Brown and Vessey, 1999; Parr et al., 1999), we argue that in the case of the Chinese organizations it is useful for ERP-adopting organizations to examine closely some of the issues related to bundling BPR with ERP. While our cases represent only a small number of ERP implementations in China, the cases still demonstrate an adequate diversity in the patterns and characteristics of ERP implementations, which allow us to develop the findings below.

\subsection{Selection of ERP Package Choice}

Selecting an ERP package is a time-consuming task that needs a set of meticulous procedures. Even though it is well documented that choosing a package that best fits the companies' business processes is the most important criteria (Everdingen et al., 2000), however this is not always the case in China. There is a range of ERP packages available in the Chinese market, ranging from popular Western products such as 'SAP', to locally developed ones such as 'Yongyou'. Despite this, Companies A, B and E, for example, selected their ERP systems based on decisions made by their headquarters, rather than on cost or other criteria. This could be part of the companies' global IT strategy to consolidate their information systems for better communication and technical support. Furthermore, the vast presence 
of foreign ERP vendors in China, which accounts for more than $70 \%$ of Chinese ERP market (CCID, 2001), boosted these foreign companies' confidence to continue using these foreign ERP systems. Given the fact that foreign ERP packages continue to play a major role in the Chinese ERP industry, perhaps local ERP vendors could only seize a greater market share by offering quality but cheaper ERP packages with solid vendor support, as seen in the cases of companies $C$ and $D$.

More research is needed to examine what the selection criteria are for choosing an ERP package for organizations in China. Specifically, to investigate the relative importance of various selection criteria adopted by the organizations and to validate the claim that choosing a package that best fits its business processes and functionalities is the most important criteria when the cost, risk of BPR and customization are being considered (Everdingen et al., 2000). A future study into how ERP packages are selected in a localized market like China may have implications for local companies as well as foreign vendors aiming to enter Chinese IT product market.

\subsection{Readiness of BPR Process}

Similar to Harrison et al's (2000) findings, we found in our cases that foreign companies are better prepared for the implementation of an ERP system as their structures and processes may already be based on modern Western management approaches, and so be more similar to the processes embedded in the ERP systems. On the other hand, Chinese companies, whether privately held or state owned, are likely to display more traditional management systems and business processes. Such traditional Chinese organizations carry with them years of cultural tradition and the far-reaching influence of Confucian dynamism, leading to a high uncertainty avoidance culture (Martinsons and Davison, 2000). People in high uncertainty avoidance cultures tend to have very structured activities and are wary of random events. Unknown or radical changes are avoided whenever possible and BPR may be too severe to be accepted by Chinese organizations.

Company $\mathrm{B}$, which was an ex-state owned beverage company, had difficulties aligning its business processes with the standard procedures embedded in the ERP package. Most of the staff had been working for the company since it was still owned by the state, and many of them were in their middle age with low levels of English language and computer knowledge. They underestimated the radical changes required by the ERP systems. More importantly, they failed to analyze their businesses processes prior to the adoption and assess their readiness in adopting the new systems in terms of the quality and the level of available resources. 
Conversely, for cases A and E, both reviewed and evaluated their internal processes prior to their ERP implementation. They identified their weaknesses and defined their objectives, which are often cited as the critical success factors for ERP implementations (Sumner, 1999; Holland et al., 1999). Perhaps one of the reasons why foreign owned companies have an edge over the Chinese local companies in this respect could be due to their accumulated experiences in implementing ERP systems in their headquarters and other branches, which might have suggested BPR as a key step before ERP implementations.

Having a thorough knowledge of current business processes is the prerequisite for conducting BPR and matching its processes with the ERP package. However, it can be a complicated and demanding task to analyze business processes, and it is rarely conducted in real world situations (Scheer and Habermann, 2000). In some cases, some ERP vendors provide business process analysis model that facilitates better understanding of complex business processes (Holland et al., 1999). Further research should be carried out to examine the usefulness of these business process analysis models, which could be a potentially useful tool in helping organizations to conduct BPR before their ERP implementations (Newell et al., 2000).

\subsection{Prefer "Matching" over "Customization"}

Our study in China has shown that companies were more willing to reengineer their processes than customize the ERP software, since only one out of five companies performed customization during their ERP implementation process. Company $\mathrm{C}$ failed in their large-scale customization effort due to the departure of the software development engineers and poor documentation of amended source codes. This observation aligns with the results from the IS literature, which calls for organizations to change the business to fit the software with minimum customization (Mabert et al., 2001; Somers and Nelson, 2001). Conversely, Companies A, D and $\mathrm{E}$ were better prepared for the ERP implementation and adjusted their business processes to meet the systems requirements. Generally, the employees from these companies were more cooperative, adaptive, flexible and received solid support from ERP vendors to guide them through the transition period.

The adopting organizations should be aware of the business processes embedded in the ERP package before purchasing the systems. Prior to any implementation, they must thoroughly analyze these processes. If the processes embedded in the ERP package are inappropriate for the adopting organization, customization could be considered. Generally, the recommendation is that customization should be discouraged as far as 
possible (Sumner, 1999) to avoid errors and allow the adopting company to make the most of newer versions and releases (Nah et al., 2001). Future research must give more attention to how to conduct an analysis on these ERP packages in order to find the package with the best fit with the business processes.

\subsection{Tendency to Over-Adjust Existing Business Processes}

Company B, for example, conducted major process reengineering, which involved several job redesigns and shuffling of manpower. However the changes were far greater than what they had expected, which caused low staff morale and productivity. There must be a balance between what is being practiced and what is required from the systems. Furthermore, reengineering should take place iteratively to take advantage of improvements from the new system (Nah et al., 2001). On the other hand, Company D simply reengineered its business processes to be consistent with the standard models and customized the system according to its own requirements. As a result, it faced few 'mismatches' during the implementation process.

When bridging the 'gap' between the functionalities and business procedures implanted in the ERP package and those required by the adopting organizations, maintaining a balance between customization and BPR is essential. To reduce any potential risk and facilitate future maintenance and upgrading of the systems, customization should be independent from the original package. This would minimize making alterations in the modules offered by ERP vendors and instead, rely more on add-ons to achieve the required functionality. However, few companies prefer to make substantial changes to their business processes (Parr and Shanks, 2000) since BPR would also increase the complexity and the cost of ERP implementation (Gattiker and Goodhue, 2000). There must be a balance between reengineering the business processes and resolving any 'mismatches' through customization. More efforts should be made to explore how organizations could minimize the impacts on the existing staff from BPR. Instead of simply. laying off surplus employees, training programs can be installed to re-skill these affected employees to prepare them for any forthcoming higher skilled jobs.

\subsection{Continuous Improvement Efforts and Strong Vendor Supports}

Management needs information on the result of ERP on business performance, which includes effective measurable project goals that meet 
business needs (Nah et al., 2001) and also as an authentication to silence any critics. To achieve success in an ERP implementation, continuous improvement efforts and strong vendor supports are important in the postimplementation period. Company A, for example, developed an environment which encouraged innovation and generation of new ideas. Also, Company $\mathrm{D}$ depended on vendors' support in terms of user training and minimum customization on the ERP systems. In addition, Company E attributed its implementation success to frequent communication and feedback among various departments.

Post-implementation review is critical as it provides a feedback channel for continuous improvement even after the new systems have been established. In any new systems implementation, there will usually be a temporary decline in productivity immediately after the implementation. However, this decline should last no more than 12 months, before it reaches the state where the ERP systems can be utilized more effectively by the adopting organizations (Mabert et al., 2001). This transition represents a period of instability with constant adjustments and adaptations to new processes. Standard activities usually involve providing continuous training for new users and cooperating with vendors to resolve bugs in the software. At this stage, preliminary benefits in adopting ERP may start to emerge (Ross and Vitale, 2000). Perhaps future research can explore more ways on shortening the transition period and to tackle the issues caused by the instability of the new systems.

\section{CONCLUSIONS}

Implementing a global product in a localized context has never been easy. Despite its potential, ERP is considered one of the most difficult systems to implement to date. The risk of implementing an ERP package in China is even higher due to the relatively backward, nonstandard management mechanisms and business processes in most Chinese companies. Taking into account these weaknesses, this paper argues that BPR could play a significant role in ERP deployment.

In this paper, we raised a number of issues associated with organizations implementing ERP systems in China. By developing an understanding of the importance of BPR as a preparatory-step to an ERP implementation, we derived five important findings. These comprise what literature suggests as key issues for an ERP implementation and integrate what our research revealed as essential issues for organizations implementing ERP systems in China. As the concept of ERP is still new to Chinese enterprises, it is natural that relatively few organizations were found to have carried out BPR as a 
pre-step for ERP implementation. As a famous Chinese saying, "well begun is half done", conducting BPR before ERP implementations should be of great help to potential Chinese ERP adopters.

The findings described in this paper are limited due to the lack of both locally developed ERP systems and locally owned company cases. This limitation was the result of the fact that it was extremely difficult to obtain access into organizations especially locally owned Chinese companies in China. The inclusion of these types of case should provide more insights into the difficulties of implementing ERP systems in a localized context, such as China with issues such as diversity in cultural background and economic conditions. Despite the limitation, we are convinced that this study is useful since there is very little research on ERP implementations in a developing country such as China (Reimers, 2002) and there can be no question about the importance of deeper understanding of the ERP implementation model for China.

Finally, we suggest that further research should include both locally developed ERP systems and locally owned company cases in a developing country to validate whether these findings apply. This research should investigate obstacles in the ERP implementations faced by foreign owned companies and locally owned companies and assess how this affects the integrated ERP implementation model for a developing country such as China.

\section{REFERENCES}

AMR 2002. Available at: www.amrresearch.com

Bingi, P., Sharma, M.K. and Godla, J. "Critical Issues Affecting an ERP Implementation", Information Systems Management, (16:3), 1999, pp. 7-14.

Brown, C. and Vessey, I. "ERP Implementation Approaches: Toward a Contingency Framework", Proceedings of the 20th International Conference on Information Systems, Charlotte, December 1999, pp. 411-416.

CCID (China Center of Information Industry Development), Available at: http://www.kingdee.com/news/zhuanti/erp/index.php

Everdingen, Y.V., Hillegersberg, J.V. and Waarts, E. "ERP Adoption by European Midsize Companies", Communications of the ACM, (43:4), April 2000, pp.27-31.

Gattiker, T.F. and Goodhue, D.L., "Understanding the Plant Level Costs and Benefits of ERP: Will the Ugly Duckling Always Turn Into a Swan?", Proceedings of the 33rd Hawaii International Conference on System Sciences, 2000.

Harrison, G.L., Mckinnon, A., Wu, A. and Chow, C. "Cultural Influences on Adaptation to Fluid Workgroups and Teams", Journal of International Business Studies, (31:3), 2000, pp. 489-505.

Holland, P. and Light, B. "A Critical Success Factors Model for ERP Implementation”, IEEE Software, (16:3), May-June 1999, pp. 30-36. 
Holland, P., Light, B. and Gibson, N. "A Critical Success Factors Model for Enterprise Resource Planning Implementation", Proceedings of the 7th European Conference on Information Systems, (1), 1999, pp. 273-297.

Huang, Z. and Palvia, P., "ERP Implementation Issues in Advanced and Developing Countries", Business Process Management, (7:3), 2001, pp. 276-284.

Jin, D. "ERP in China", Computer Weekly, 6 June, 2001.

Katzenstein, G. and Lerch, F.J., "Beneath the Surface of Organizational Processes: a Social Representation Framework for Business Process Redesign", ACM Transactions on Information Systems, (18:4), October 2000, pp. 383-422.

Krumbholz, M., Galliers, J., Coulianos, N. and Maiden, N.A.M., "Implementing Enterprise Resource Planning Packages in Different Corporate and National Cultures", Journal of Information Technology, (15:4), December 2000, pp. 267-279.

Lee, Z. and Lee, J., "An ERP implementation Case Study From a Knowledge Transfer Perspective", Journal of Information Technology, (15:4), December 2000, pp. 281-288.

Mabert, V.A., Soni, A. and Venkataramanan, M.A., "Enterprise Resource Planning: Common Myths Versus Evolving Reality”, Business Horizons, (44:3), May-June 2001, pp. 69-76.

Martinsons, M.G. and Davison, R.M., "Cultural Considerations in Business Process Change", Department of Information Systems, City University of Hong Kong, 2000. Available at http://www.is.cityu.edu.hk/Research/Publication/working_paper00.htm

Nah, F. H., Lau, L. S. and Kuang, J. H., "Critical Factors for Successful Implementation of Enterprise Systems”, Business Process Management Journal, (7:3), 2001, pp. 285-296.

Newell, S., Swan, J.A. and Galliers, R.D., "A Knowledge-Focused Perspective on the Diffusion and Adoption of Complex Information Technologies: the BPR Example", Information Systems Journal, (10:3), 2000, pp. 239-259.

Newell, S., Huang, J.C. Galliers, R.D. and Pan, S.L., "Implementing Enterprise Resource Planning and Knowledge Management Systems in Tandem: Fostering Efficiency and Innovation Complementarity”, Information \& Organization, (13:1), 2003, pp. 25-52.

Newman, $M$ and Sabherwal, R., "Determinants of Commitment to Information Systems Development: a Longitudinal Investigation”, MIS Quarterly, (20:1), March 1996, pp. 23 32.

Parr, A.N. and Shanks, G., "A Taxonomy of ERP Implementation Approaches", Proceedings of the 33rd Hawaii International Conference on System Sciences, (7), 2000.

Parr, A.N., Shanks, G. and Darke, P., "The Identification of Necessary Factors for Successful Implementation of ERP Systems", in: O. Ngwenyama et al. (eds.): New Information Technologies in Organizational Processes, Boston: Kluwer Academic, 1999, pp. 99-119.

Reimers, K., "Implementing ERP Systems in China", Proceedings of the 35th Hawaii International Conference on System Sciences, (8), 2002.

Ross, J.W. and Vitale, M.R. "The ERP Revolution: Surviving vs. Thriving", Information Systems Frontiers, (2:2), August 2000, pp. 233-241.

Scheer, W. and Habermann, F., "Making ERP a Success", Communications of the ACM, (43:4), April 2000, pp. 57-61.

Soh, C., Kien, S.S. and Tay-Yap, J., "Cultural Fits and Misfits: Is ERP a Universal Solution?", Communications of the ACM, (43:4), April 2000, pp. 47-51.

Somers, T.M. and Nelson, K., "The Impact of Critical Success Factors across the Stages of Enterprise Resource Planning Implementations", Proceedings of the 34th Hawaii International Conference on System Sciences, (8), 2001.

Sumner, M., "Critical Success Factors in Enterprise Wide Information Management Systems Projects", Proceedings of the Americas Conference on Information Systems (AMCIS), 1999, pp. 232-234. 
Walsham, G., Interpreting Information Systems in Organizations, Chichester, England: Wiley, 1993.

Walsham, G., "Interpretive Case Studies in IS Research: Nature and Method", European Journal of Information Systems, (4:2), 1995, pp. 74-81.

Yin, R. Case Study Research: Design and Methods, Second Edition, Thousand Oaks, CA: Sage, 1994.

\begin{abstract}
About the Authors
Gary S C PAN is a $\mathrm{PhD}$ candidate in the Department of Computation, University of Manchester Institute of Science and Technology, UK. His research interests include implementation of enterprise systems and information systems project failure. He has presented in several major conferences and has won best track paper in the British Academy of Management conference in 2002. He can be reached by e-mail at s.pan@postgrad.umist.ac.uk

Shan L. PAN is Assistant Professor in the Department of Information Systems of School of Computing at the National University of Singapore. His primary research focuses on the recursive interaction of organizations and information technology (enterprise systems), with particular emphasis on issues related to work practices, cultures and structures from a knowledge perspective. He has published in IEEE Transactions on Engineering Management, Journal of Strategic Information Systems, Communications of ACM, European Journal of Information Systems, and Decision Support Systems. He can be reached by e-mail at pansl@comp.nus.edu.sg

Xin Xin CHEN is a research student in the Department of Information Systems of School of Computing at the National University of Singapore. Her primary research interests focuses on the strategic issues involved in implementing enterprise systems. She can be reached by e-mail at chenxinx@comp.nus.edu.sg

Donal FLYNN spent 11 years in the UK IT industry as programmer, database designer and project consultancy. He has degrees in Chemical Physics (BSc University of Kent), Sociology \& Psychology (MSc Imperial College, University of London) and Conceptual Modelling ( $\mathrm{PhD}$ University of East Anglia). His research interests are in the socio-organizational factors and processes that underlie the interaction between IT systems and their human and organizational contexts. $\mathrm{He}$ is currently Senior Lecturer in Information Systems, Department of Computation, University of Manchester Institute of Science and Technology. He can be reached by e-mail at donal.flynn@umist.ac.uk or visit his website at http://www.co.umist.ac.uk/ department/staff_details_ac.php?staff_id=DJF
\end{abstract}

